\title{
Hemşirelik lisans ve lisansüstü programlarında yürütülen evde bakım hemşireliği dersinin incelenmesi
}

\author{
Belçim EDE ${ }^{\mathrm{a}}$, Nurcan UYSAL ${ }^{\mathrm{b}}$
}

\section{ÖZET}

Amaç: Bu araştırma, Yükseköğretim Kurulu'na bağlı üniversitelerin Hemşirelik Lisans ve Lisansüstü düzeyinde verilen "Evde Bakım Hemşireliği" dersinin öğretimine ilişkin durumu belirlemek amacıyla yapılmıştır. Yöntem: Araştırma tanımlayıcı olarak planlanmıştır. Araştırmanın evrenini, 2020 yılı içerisinde Yükseköğretim Kurulu'na bağlı olarak eğitim veren hemşirelik lisans ve lisansüstü programlar oluşturmuş olup 113'ü devlet ve 102'si vakıf olmak üzere toplam 215 Hemşirelik Okulu'nun web sayfası incelenmiştir. Veri toplama aracı olarak araştırmacılar tarafindan oluşturulan soru formu kullanılmıştır. Veriler 1-31 Ocak 2020 tarihleri arasında hemşirelik programlarının web sitelerindeki içeriklerin taranmasıyla elde edilmiștir. Bulgular: İncelenen web sayfalarına göre; hemşirelik lisans ve lisansüstü eğitim veren vakıf ve devlet üniversitelerinin \%22,8'inde Evde Bakım Hemşireliği dersinin müfredatta yer aldığı, \%77,2'inde yer almadığı belirlenmiştir. Dersin adı, içeriği, amacı, dersin öğrenim çıktıları açısından farklılıklar bulunduğu belirlenmiş̧tir. Programların \%2,0'ında zorunlu ders olarak verildiği, \%98,0 teorik, \%2,0 uygulama saati olduğu belirlenmiş̧ir. Üniversitelerin web sayfalarındaki Bologna Bilgi Paketleri incelendiğinde \%75,0'ında dersin amacının açıklandığı, \%83.4'ünde öğrenim kazanımlarının paylaşıldığı saptanmıştır. Çoğunlukla bilişsel öğrenim kazanımlarına yer verildiği görülmüştür. Sonuç: Üniversitelerin web sayfalarında yer alan Evde Bakım Hemşireliği dersi incelendiğinde lisans ve lisansüstü düzeyde dersin amaç ve öğrenim kazanımlarında farklılıkların olmadığı saptanmıştır. Dersin psikomotor beceri kazanımları belirtilmesine rağmen uygulamaya yer verilmediği belirlenmiştir.

Anahtar Kelimeler: Bologna süreci, evde bakım hemşireliği, hemşirelik eğitimi

Investigation of home care nursing course in undergraduate and postgraduate programs of nursing

\begin{abstract}
Objective: This research was carried out in order to determine the situation regarding the teaching of the "Home Care Nursing" course given at the Nursing Undergraduate and Postgraduate level at the universities affiliated to the Council of Higher Education. Methods: The research was planned descriptively. The universe of the research has been created in 2020, undergraduate and graduate programs in nursing under the Council of Higher Education, and the web pages of 215 Nursing Schools, 113 of which are state and 102 are foundations, have been examined. The questionnaire created by the researchers was used as the data collection tool. The data were obtained by scanning the content on the websites of nursing programs between 1-31 January 2020. Results: According to the analyzed web pages; It was determined that Home Care Nursing course is included in the curriculum in $22.8 \%$ of foundations and state universities that provide undergraduate and postgraduate education in nursing, but not in $77.2 \%$. It has been determined that there are differences in terms of the name, content, purpose and learning outcomes of the course. It was determined that $2.0 \%$ of the programs were given as a compulsory course, $98.0 \%$ theoretical and $2.0 \%$ practice hours. When the Bologna Information Packages on the web pages of the universities were examined, it was determined that the purpose of the course was explained in $75.0 \%$ and the learning outcomes were shared in $83.4 \%$. It observed that cognitive learning outcomes were mostly included. Conclusions: When the Home Care Nursing course on the web pages of the universities was examined, it was found that there were no differences in the aim and learning outcomes of the course at undergraduate and graduate levels. Although the psychomotor skill acquisitions of the course were stated, it was determined that the application was not included.
\end{abstract}

Keywords: Bologna process, home care nursing, nursing education

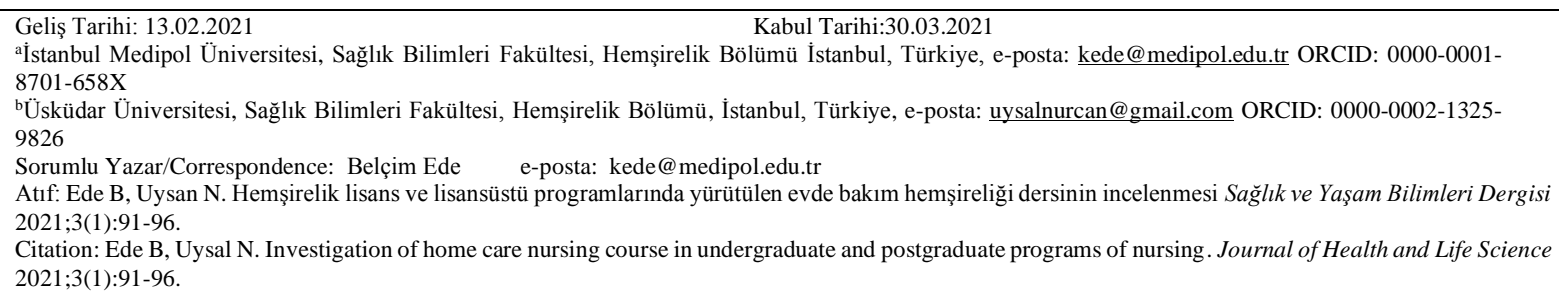




\section{GíRiş}

Dünya genelinde nüfusun demografik verilerindeki değişiklikler, teknolojik, politik değişimler, pandemi düzeyindeki salgın hastalıklar, yaşlı ve engelli nüfusun giderek artıyor olması, kronik hastalıkların artışı gibi birçok durum bakım sorunlarını gündeme getirmektedir. Bu nedenle ülkeler, bakım hizmetlerinin daha düşük maliyette ancak kaliteli ve kapsamlı bir şekilde bireylere ulaştırabilmek için evde bakım hizmetlerini geliştirmenin üzerinde durmaktadır. ${ }^{1}$ Evde bakım hizmetleri, bireyin evde profesyonel anlamda bakım ve tedavisini içermekte olup, farklı ve karmaşık uygulamaları kapsamaktadır. Birey ve yakınlarının fiziksel, ruhsal, sosyal ve kültürel tüm yönleriyle değerlendirilebilmesi açısından evde bakım hizmetleri bir ekip hizmeti olup bu ekibin en büyük bölümünü evde bakım hemşireleri oluşturmaktadır. ${ }^{2,3}$ Evde bakım hemşireliği; koruyucu, tedavi ve rehabilite edici sağlık hizmetlerinin, birey ve ailesine yaşadıkları ortamda gerekli hemşirelik bakımını belirleme, planlama, uygulama ve değerlendirme yoluyla sunulmasıdır. Evde bakım hemşiresi birey ve ailesinin sağlı̆̆ını fiziksel, sosyal ve duygusal yönden bir bütün olarak değerlendirir. ${ }^{4,5}$ Evde bakım hemşireleri, hastalar ve hastaların aileleriyle daha fazla zaman geçirdiğinden, evde bakım ekibinin en temel üyesi olup evde bakım hizmetlerinin yerine getirilmesinde önemli bir paya sahiptir. Evde bakım hemşireleri özellikle bakım verici rolü açısından rehabilitasyonun ve tedavinin etkin olmasında, bireyin mevcut sağlık durumunun iyileştirilmesinde, bakım destek elemanlarının denetimlerinde önemli rollere sahiptir. ${ }^{6}$ Ancak ülkemizde Evde Bakım Hizmetleri Uygulama Yönetmeliği (2005), ${ }^{7}$ Evde Sağlık Hizmetlerinin Uygulama Usul ve Esasları Hakkında Yönerge ${ }^{8}$ (2010)'ye göre evde bakım hemşiresinin sorumlulukları net olarak tanımlı değildir. Yönetmeliğe göre; evde bakım hemşiresinin görevleri ilaç uygulama, gözlem ve kayıt, hastalık hakkında birey ve ailesini bilgilendirme, sağlık eğitimi ve sorumlu hekimin verdiği diğer görevleri yapma şeklinde açıklanmıştır (Evde bakım Hizmetleri Sunumu Hakkında Yönetmelik 2005; Sağlık Bakanlığınca Sunulan Evde Bakım Hizmetlerinin Sunumu Hakkında Yönerge 2010). Hemşirelik Yönetmeliğinde $(2011)^{9}$ evin ortamını değerlendirme, bakım destek elemanlarının denetimini yapma, sağlık eğitimi, bireylerin şikayet ve isteklerini dinleme, değerlendirme ve ilgili birimlere yönlendirme şeklinde belirtilmiştir. İlgili yönetmeliklerde evde bakım hemşiresinin sahip olması gereken yetkinlikler belirtilmemekle birlikte tedavi, bakım uygulamaları ve sağlık eğitimi rolleri belirtilmiştir.

Evde sağlık bakım hizmetlerinin sunulmasında ve bireylerin bakım gereksinimlerinin en iyi şekilde karşılanmasında, evde bakım hemşiresine büyük sorumluluklar düşmektedir. Ancak yapılan çalışmalar, evde bakım hemşirelerinin rol ve sorumluluklarını gerçekleştirirken çeşitli zorluklar yaşadığını ortaya koymuştur. $\mathrm{Bu}$ zorluklardan bazılarının hemşirelerin mesleki bilgi beceri eksikliği, iletişim becerilerinin yetersizliği, hemşirenin kendini yeterli hissetmemesi ve işini sevmemesi olduğu belirlenmiştir. ${ }^{10,11} \mathrm{Bu}$ bağlamda diğer hemşirelik derslerinin yanı sıra "Evde Bakım Hemşireliği" dersinin önemi ortaya çıkmaktadır. $\mathrm{Bu}$ alanda hizmet verecek olan hemşirelerin, bireylere nitelikli ve kaliteli evde bakım hizmeti sunabilmesi için istenilen düzeyde eğitim almasını gerekli kılmaktadır. Mezuniyet sonrasında ise hızla değişen sağlık bakım sistemine uyum sağlaması ve kendilerini sürekli geliştirmeleri önemlidir. Amerika Birleşik Devletleri, Avrupa ve Kanada gibi bazı ülkelerde, evde bakım hemşireliği dersi birçok hemşirelik okulunun lisans, yüksek lisans veya doktora programlarında yer almaktadır. Ülkemizde de benzer şekilde yürütülmektedir fakat Amerika Birleşik Devletleri’nde lisans düzeyinde eğitim almış hemşireler için Amerikan Hemşireler Birliği (ANA) tarafından beş yılda bir yenilenen kemoterapi, diyaliz gibi farklı uygulamalara yönelik sekiz hafta süren sertifika programları düzenlenmektedir. ${ }^{14}$ Amerikan Hemşirelik Yetkilendirme Merkezi (American Nurses Credentialing Center) tarafından genel ve klinik uzman düzeylerinde verilen "Evde Sağlık Klinik Hemşire Uzmanlık Sertifikası" alabilmek için en az lisans düzeyinde eğitim almış olmak zorunludur ve evde bakım hemşiresi olarak çalışabilmek için sertifika dışında minimum iki yıllık bir deneyime sahip olma şartı aranmaktadır. Ülkemizde ise bazı hemşirelik fakülteleri ve Evde Bakım Derneği tarafindan düzenlenen yaklaşı 160 saat süren sertifika programları bulunmakta ve bu sertifika programlarına başvuruda bulunan kişilerin en az lisans mezunu hemşire, sağlı memuru ya da ebe olması gerekmektedir. Ayrıca evde bakım hemşiresi olabilmek için deneyim şartı aranmamaktadır. ${ }^{4}$ Ulusal hemşirelik literatürü incelendiğinde bu dersin hemşirelik okullarındaki mevcut durumunu ortaya koyan bir çalışmaya rastlanmamıştır. $\mathrm{Bu}$ nedenle ülkemizdeki hemşirelik eğitiminin lisans ve lisansüstü düzeyinde yer alan "Evde Bakım Hemşireliği”" dersinin amaç, içerik ve öğrenim kazanımları açısından incelenerek mevcut durumunun ortaya konulması hedeflenmiştir. $\mathrm{Bu}$ incelemenin, ders içeriği ve öğrenim kazanımlarının geliştirilmesi açısından yararlı olacağı düşünülmektedir.

\section{Araştırmanın Soruları}

1.Yükseköğretim Kurulu'na (YÖK) bağlı üniversitelerin hemşirelik lisans ve lisansüstü programlarında Evde Bakım Hemşireliği dersi yer almakta midir?

2. Dersin sorumlu personelinin akademik özellikleri nasildir?

3. Evde Bakım Hemşireliği dersinin kuramsal ve uygulama içeriğine ilişkin özellikler nelerdir? 


\section{YÖNTEM}

\section{Araştırmanın amacı ve türü}

$\mathrm{Bu}$ çalışma Yükseköğretim Kuruluna bağlı üniversitelerin hemşirelikte lisans ve lisansüstü programlarında yer alan "Evde Bakım Hemşireliği" dersini incelemek amacıyla tanımlayıcı olarak planlanmıştır.

\section{Araştırmanın evreni ve örneklemi}

Çalışma evrenini, Yükseköğretim Bilgi Yönetim Sisteminde aktif olarak hemşirelik bölümü bulunan 215 üniversite oluşturmuştur (https://istatistik.yok.gov.tr). ${ }^{15}$ Çalışmada örneklem seçimine gidilmemiş olup tüm üniversitelerin hemşirelik bölümlerinin web sayfaları incelenmiştir.

\section{Veri toplama araçları}

$\mathrm{Bu}$ çalışmanın verileri araştırmacılar tarafindan oluşturulan anket formuyla elde edilmiştir. $\mathrm{Bu}$ formda Evde Bakım Hemşireliği dersinin lisans ve lisansüstü programlarında olup olmadığ yöntemi, dersin programdaki tam adı, seçmeli/zorunlu olma durumu ve ders bilgi paketinde dersin öğrenim kazanımlarının olup olmadığını değerlendiren sorular yer almaktadır.

\section{Verilerin toplanması}

Veriler 1-30 Ocak 2020 yılında, veri toplama formunda yer alan sorular doğrultusunda üniversitelerin hemşirelik bölümlerinin web sayfaları incelenerek toplanmıştır. Verilerin web sayfalarından elde edilmesi nedeniyle etik kurul izni alınması gerekli görülmemiştir.

\section{Verilerin değerlendirilmesi}

Araştırmada elde edilen veriler tanımlayıcı istatistiklerden sayı ve yüzde hesabı kullanılarak SPSS 21.0 Windows paket programında analiz edilmiştir.

\section{Araştırmanın sınırlılıkları}

Evde Bakım Hemşireliği dersinin incelenmesine yönelik yapılan bu araştırmada veriler, üniversitelerin web sitelerinde yer alan bilgilerden elde edildiği için web sayfalarında yer alan bilgilerin yetersiz olması nedeniyle tüm hemşirelik bölümlerini kapsamaması araştırmanın sınırlılığını oluşturmaktadır.

\section{BULGULAR}

Yükseköğretim Kuruluna bağlı üniversitelerin hemşirelik bölümlerinin \%52.5'i devlet, \%47.5'i vakıf üniversitesinde yer almaktır (Tablo 1).

Tablo 1. Hemşirelik eğitimi veren kurumlarının türü (n=215)

\begin{tabular}{|c|c|c|c|c|c|c|}
\hline & \multicolumn{2}{|c|}{ Devlet } & \multicolumn{2}{|c|}{ Vakıf } & \multicolumn{2}{|c|}{ Toplam } \\
\hline & $\mathrm{n}$ & $\%$ & $\mathrm{n}$ & $\%$ & $\mathrm{n}$ & $\%$ \\
\hline Hemşirelik Fakültesi & 14 & 6.5 & 2 & 0.9 & 16 & 7.4 \\
\hline Sağlık Bilimleri Fakültesi & 65 & 30.2 & 88 & 41.0 & 153 & 71.2 \\
\hline Sağlık Yüksekokulu & 34 & 15.8 & 12 & 5.6 & 46 & 21.4 \\
\hline Toplam & 113 & 52.5 & 102 & 47.5 & 215 & 100 \\
\hline
\end{tabular}

İncelenen 215 üniversitenin hemşirelik programlarının yalnızca \%22.8'inde (n=49) Evde Bakım Hemşireliği dersinin yer aldığ 1 belirlenmiştir. Dersin yer aldığ programların Bologna Süreci Ders Bilgi Paketleri incelendiğinde yalnızca \%73.5'inde $(n=36)$ dersin içerik bilgisine ulaşılmıştır. Dersin lisans, yüksek lisans ve doktora düzeyinde yer aldığı belirlenmiş olup \%75.6'sı lisans, \%12.2'si yüksek lisans ve \% 12.2'si doktora düzeyinde verildiği belirlenmiştir. Lisans düzeyindeki programların yalnızca birinde (\%2) bu dersin zorunlu olarak verildiği, geri kalan programların \%98'inde seçmeli olarak yer aldığ Dersin tüm programlarda teorik olarak işlendiği, yalnızca bir hemşirelik programında son sınıf intörnlük uygulamasının içerisinde seçmeli klinik uygulama olarak yer verildiği belirlenmiş fakat uygulamanın detayları ile ilgili bilgilere ulaşılamamıştır. Dersin yer aldığ 1 hemşirelik programlarının \%89.8'inde ders isminin "Evde Bakım Hemşireliği”" \%10.2'sinde ise "Evde Sağlık Bakımı Yönetimi, Geriatri ve Evde Bakım Hemşireliği, Evde Hasta Bakımı, Evde Bakım, Yaşlılık ve Evde Bakım" ismi ile yer aldığ belirlenmiştir (Tablo 2).
Evde bakım hemşireliği dersinden sorumlu akademik personele ilişkin veriler incelendiğinde; \%88.9'unun hemşirelik lisans programından mezun olduğu, \%36.1'inin doktora öğretim üyesi olarak çalıştığı, \%11.1'inin uzmanlık alanının, hemşirelik dışında (ebelik, tıp, sağlık eğitimi vb) olduğu saptanmıştır (Tablo 2).

Ders içeriklerine ulaşılan programların Bologna sürecine göre yapılandırılmış ders bilgi paketleri incelendiğinde, \% 75'inde dersin amaçları, \%83.4'ünde dersin öğrenim kazanımlarının yazılı olduğu görülmüştür (Tablo 3).

Öğrenim kazanımlarının çoğunlukla bilişsel düzeyde olduğu, psikomotor ve duyuşsal beceri kazanımlarına çok az yer verildiği belirlenmiştir. Yüksek lisans ve doktora programları ile lisans düzeyindeki dersin amaçları karşılaştırıldığında bir farklılık olmadığı tespit edilmiştir.

Tablo 2. Evde Bakım Hemşireliği dersine ilişkin tanıtıcı bilgiler 


\begin{tabular}{|c|c|c|}
\hline Tanitıcı bilgiler & n & $\%$ \\
\hline \multicolumn{3}{|c|}{ Hemşirelik bölümlerinde dersin olma durumu $(\mathrm{n}=215)$} \\
\hline Var & 49 & 22.8 \\
\hline Yok & 103 & 47.9 \\
\hline Veri elde edilemeyen & 63 & 29.3 \\
\hline \multicolumn{3}{|c|}{ Dersin yer aldığı program düzeyleri $(n=49)$} \\
\hline Lisans & 37 & 75.6 \\
\hline Yüksek Lisans & 6 & 12.2 \\
\hline Doktora & 6 & 12.2 \\
\hline \multicolumn{3}{|c|}{ Ders içeriğinin paylaşılma durumu $(n=36)$} \\
\hline Lisans & 30 & 83.3 \\
\hline Yüksek Lisans & 2 & 5.5 \\
\hline Doktora & 4 & 11.2 \\
\hline \multicolumn{3}{|c|}{ Dersin zorunlu/seçmeli olma durumu $(n=49)$} \\
\hline Zorunlu & 1 & 2.0 \\
\hline Seçmeli & 48 & 98.0 \\
\hline \multicolumn{3}{|l|}{ Dersin işleniş biçimi (n=49) } \\
\hline Teorik & 48 & 98.0 \\
\hline Uygulama & 1 & 2.0 \\
\hline Teorik + Uygulama & 0 & 0 \\
\hline \multicolumn{3}{|c|}{ Ders bilgi paketinde dersle ilgili veriler $(n=49)$} \\
\hline Var & 36 & 73.5 \\
\hline Yok & 13 & 26.5 \\
\hline \multicolumn{3}{|l|}{ Dersin adı $(n=49)$} \\
\hline Evde bakım hemşireliği & 44 & 89.8 \\
\hline \multicolumn{3}{|l|}{$\begin{array}{l}\text { Evde sağlık bakımı yönetimi } \\
\text { Geriatri ve evde bakım hemşireliği }\end{array}$} \\
\hline Evde hasta bakımı & 5 & 10.2 \\
\hline \multicolumn{3}{|l|}{ Evde bakım } \\
\hline \multicolumn{3}{|c|}{ Yaşlilık ve evde bakım hizmetleri } \\
\hline \multicolumn{3}{|c|}{$\begin{array}{l}\text { Dersin sorumlu akademik personelinin özelliklerinin } \\
\text { Dağılımı }(n=36)\end{array}$} \\
\hline \multicolumn{3}{|c|}{ Mezun olunan lisans programı } \\
\hline Hemşirelik & 32 & 88.9 \\
\hline $\begin{array}{l}\text { Sağlık bilimleri (ebelik, tıp, sağlık } \\
\text { eğitimi vb.) }\end{array}$ & 4 & 11.1 \\
\hline \multicolumn{3}{|l|}{ Dersi verenlerin akademik unvanı } \\
\hline Profesör & 10 & 27.8 \\
\hline Doçent & 6 & 16.7 \\
\hline Doktora öğretim üyesi & 13 & 36.1 \\
\hline Öğretim görevlisi & 7 & 19.4 \\
\hline \multicolumn{3}{|l|}{ Uzmanlık alanı } \\
\hline Hemşirelik & 32 & 89,9 \\
\hline Hemşirelik dişından & 4 & 11.1 \\
\hline
\end{tabular}

Ders müfredatında yer alan konular benzerliklerine göre gruplandırıldıklarında 19 konu başlığı elde edilmiştir. Diğer konu başlığı altında ise 11 konu yer almıştır. En çok benzerlik gösteren konular sırasıyla Evde Bakımın Tanımı-Tarihsel Gelişimi-Temel Kavramlar (\%55.5), Evde bakım ekibinin görev, yetki ve sorumlulukları (\%44.4) Kronik Hastalıklarda Evde Bakım Yönetimi (diyabetli hasta, kronik böbrek yetmezliği vb.) (\%41.6) olarak belirlenmiştir (Tablo 3).

\section{TARTIŞMA}

Bireylerin sağlığının korunması ve geliştirilmesi için birinci basamak sağlık hizmetlerindeki gereksinim, buna ek olarak yaşlı nüfusun ve kronik hastalıkların artması, engelli bireylerin bakımı, Covid-19 pandemisi nedeniyle bireylerin evde izole olmaları evde bakım hemşiresine olan ihtiyacı ortaya çıkarmıştır. $\mathrm{Bu}$ bağlamda, hemşirelik müfredatında evde bakım hemşireliği dersinin yer alması önem arz etmektedir.

Tablo 3. Evde Bakım Hemşireliği dersinin öğrenim kazanımları ve kuramsal içeriği $(n=36)$

\begin{tabular}{|c|c|c|}
\hline Öğrenim kazanımları ve kuramsal özellikler & $\mathbf{n}$ & $\%$ \\
\hline \multicolumn{3}{|l|}{ Dersin amacı } \\
\hline Var & 27 & 75.0 \\
\hline Yok & 9 & 25.0 \\
\hline \multicolumn{3}{|l|}{ Dersin öğrenim kazanımlar } \\
\hline Var & 30 & 83.4 \\
\hline Yok & 6 & 16.6 \\
\hline \multicolumn{3}{|l|}{ Ders konuları } \\
\hline $\begin{array}{l}\text { Evde bakımın tanımı, tarihsel gelişimi, temel } \\
\text { kavramlar, yasal düzenlemeler ve politik konular }\end{array}$ & 20 & 55.5 \\
\hline Evde bakım ekibinin görev, yetki ve sorumlulukları & 16 & 44.4 \\
\hline $\begin{array}{l}\text { Kronik hastalıklarda evde bakım yönetimi (diyabetli } \\
\text { hasta, KBY) }\end{array}$ & 15 & 41.6 \\
\hline $\begin{array}{l}\text { Türkiye'de evde bakım hemşireliği ve mevcut } \\
\text { durumu }\end{array}$ & 15 & 41.6 \\
\hline $\begin{array}{l}\text { Özel durumlarda evde bakım hizmetleri (mental } \\
\text { sağlık sorunu olan, cerrahi, demansl, inme, yara, } \\
\text { stoma, onkoloji, inkontinans hastası, psikiyatrik evde } \\
\text { hasta bakımı vb.) }\end{array}$ & 15 & 41.6 \\
\hline Evde bakımda yaşanan etik sorunlar & 14 & 38.8 \\
\hline Dünya'da evde bakımın mevcut durumu & 12 & 33.3 \\
\hline Yaşlılıkta evde bakım & 10 & 27.7 \\
\hline $\begin{array}{l}\text { Evde sağlık eğitimi, kayıt tutma ve danışmanlık } \\
\text { ilkeleri }\end{array}$ & 8 & 22.2 \\
\hline $\begin{array}{l}\text { Evde bakımın sürdürülmesinde hasta ve aile üyeleri } \\
\text { ile iletişim }\end{array}$ & 6 & 16.6 \\
\hline $\begin{array}{l}\text { Dünya'da ve Türkiye'de evde bakım vericiler ve } \\
\text { yaşadıkları sorunlar }\end{array}$ & 6 & 16.6 \\
\hline $\begin{array}{l}\text { Evde bakım hemşiresinin gereksinim saptaması, } \\
\text { evde bakım sürecinin planlanması, uygulanması ve } \\
\text { değerlendirilmesi }\end{array}$ & 5 & 13.8 \\
\hline $\begin{array}{l}\text { Evde sağlık bakımında rehabilitasyon ve sosyal } \\
\text { hizmet }\end{array}$ & 5 & 13.8 \\
\hline $\begin{array}{l}\text { Doğum öncesi ve doğum sonu anne ve çocuk } \\
\text { bakımı }\end{array}$ & 5 & 13.8 \\
\hline Evde solunum desteği & 5 & 13.8 \\
\hline Evde hospis, terminal dönemi ve palyatif bakımı & 5 & 13.8 \\
\hline Evde bakım hizmetlerinde sağlığın geliştirilmesi & 4 & 11.1 \\
\hline $\begin{array}{l}\text { Evde sağlık bakımında ilaç tedavisi enteral ve } \\
\text { parenteral beslenme } \\
\text { Diğer }\end{array}$ & 4 & 11.1 \\
\hline $\begin{array}{l}\text { Evde bakımda kullanılan hemşirelik modelleri } \\
\text { Engelli bireylerde evde bakım } \\
\text { Evde bakımda teknoloji ve ekipman kullanımı } \\
\text { Evde bakımda öncelikli gruplar } \\
\text { Evde bakımda infüzyon terapisi }\end{array}$ & & \\
\hline Evde ağrı yönetimi & 3 & 8.3 \\
\hline Evde bakımda enfeksiyon kontrolü & & \\
\hline Evde bakımda tamamlayıcı tıp uygulamaları & & \\
\hline Evde beklenmeyen ve acil durumların yönetimi & & \\
\hline Evde bakım hemşireliğinde ihmal ve istismar & & \\
\hline $\begin{array}{l}\text { Evde bakım hemşiresinin deneyimlerinin } \\
\text { paylaşılması }\end{array}$ & & \\
\hline
\end{tabular}

$\mathrm{Bu}$ çalışmadan elde edilen sonuçlara göre, bu dersin tüm hemşirelik bölümlerinde olmadığ dersin seçmeli olduğu ve uygulamaya yer verilmediği görülmüştür. Dersin öğrenme hedefleri incelendiğinde; öğrenim kazanımlarının çoğunlukla bilişsel hedefler üzerine yönelmiş olduğu, duyuşsal ve beceri kazanımlarına ilişkin hedeflerin çok az olduğu görülmektedir. Yükseköğretim Kuruluna bağlı üniversitelerin eğitim standartlarını Bologna Süreci'ne uyumlandırmaları bazı kriterlerin yerine getirilmesini gerektirir. Bunlardan bazıları, ders bilgi paketlerinin hazırlanarak paylaşıma açılması, dersin amacı, öğretim yöntemleri ve öğrenme kazanımlarının belirlenmesidir. Birçok hemşirelik bölümünün web sitelerinden ders bilgi paketlerine ulaşılamamış olması ve verilerin 
yetersiz olması nedeniyle bu sonuçlar elde edilmiş olabilir.

Bu çalışmada evde bakım hemşireliği ders içeriğinin "Halk Sağlığı Hemşireliğì" dersine entegre eden hemşirelik okullarının çoğunlukta olduğu saptanmıştır. Halk sağlığ hemşiresi, ev ziyaretleri yaparak ya da toplum sağlığı merkezlerinde sağlık eğitimleri planlayarak, sağlığın korunması, geliştirilmesi ve hastalıkların önlenmesinde önemli rol oynar. ${ }^{12,13}$ Evde bakım hemşiresi ise bakım gereksinimi olan bireylerin ihtiyaç duyduğu hemşirelik bakımını sunmak ve sağlığına yeniden kavuşturulması üzerine odaklanır. ${ }^{14}$ Halk sağlığı hemşireliği ve evde bakım hemşireliğinin ortak yönleri bulunmakla birlikte her ikisinin kendi içinde ayrı birer uzmanlık alanı olduğu gerçeğini değiştirmemektedir. ${ }^{12} \mathrm{Bu}$ nedenle bu iki dersin ayrı ayrı hemşirelik müfredatında yer alması önemlidir. Evde bakım hemşiresinin görev, yetki ve sorumluluklarının yönetmeliklerde, halk sağlı̆̆ı hemşiresi gibi açık olmaması, alanda çalışacak hemşirelerin belirlenmesinde net kriterlere göre hareket edilmemesine ve alanda çalışan hemşirelerin yeterli donanıma sahip olmamasından kaynaklı bazı zorluklar yaşamasına neden olabilir.

Evde bakım hemşireliği dersini yürüten akademik personele ilişkin veriler incelendiğinde; büyük çoğunluğunun hemşirelik lisans programından mezun olduğu ve bu alanda uzmanlaştıkları saptanmıştır. $\mathrm{Bu}$ durum hemşirelik bilgisinin artması, gelişmesi, bakım uygulamalarının derinleşmesi, kalitesinin artması, etkin ve verimli hizmet sunulması, uygulama hatalarının azaltılması ve mesleki bağlılı̆̆ın oluşabilmesi için önemlidir. Dersin öğretim yöntemleri lisans ve lisansüstü düzeyde incelendiğinde ise; düz anlatım, soru yanıt, grup çalışması, tartışma etkinliği gibi öğretim tekniklerinin sıkça kullanıldığı ve ders değerlendirme yöntemi ve geçme kriterlerinin yalnızca yazılı sınav üzerinden değerlendirildiği belirlenmiştir. Hemşirelik lisans eğitiminde öğrencinin eğitimci ile birlikte bilişsel, duyuşsal ve psikomotor becerileri kazanması beklenirken, yüksek lisans ve doktora düzeyinde öğrencinin bu becerileri daha bağımsız yerine getirebilmesi hedeflenmektedir. Evde bakım hemşireliğinin ders içerikleri incelendiğinde, evde stoma bakımı, yara bakımı, enteral ve parenteral beslenme, infüzyon terapisi, kemoterapi alan hastanın bakımı, diyabeti, demansı, inmesi, böbrek yetmezliği olan ya da doğum öncesi ve doğum sonrası bakım gibi uygulama gerektiren konuların olduğu ve bu konulara göre amaçların yazıldığı saptanmıştır. Bu nedenle evde bakım hemşireliği dersinin öğrenim hedeflerinin lisans ve lisansüstü düzeyde farkl1lıklar içermesi ve alan uygulaması yapılmasını gerekli kılmaktadır.

Ders içeriklerinde yer alan konuların 30 başlikta değişkenlik gösterdiği belirlenmiştir. Çalışmanın bu bulgusu, evde bakım hemşireliği dersi müfredat içeriklerinde önemli farklılıklar olduğunu düşündürmektedir. Bu farklılığın lisans ve lisansüstü programlar arasında olması beklenen bir durumdur ancak lisans programında ders içeriklerinin benzer olması beklenir.

\section{SONUÇ}

Evde sağlık bakım gereksinimi olan bireylerin ihtiyaçlarını karşılayabilmek adına evde bakım hizmetlerinin içeriği farklılaşmakta, bu alanda çalışacak evde bakım hemşirelerinin yetiştirilmesi önemli hale gelmektedir. Evde bakım hemşireliğinin geliştirilmesi için hemşirelik eğitim programlarında bu dersin bulunması yararlı olacaktır. Yükseköğretim Kurumuna bağlı tüm üniversitelerin hemşirelik web sayfaları incelendiğinde, programların yalnızca dörtte birinde bu dersin olduğu, lisans ve lisansüstü düzeyi öğrenim kazanımlarında farklılıklar olmadığı ve ders içeriklerinde farklılıklar olduğu belirlenmiştir. Evde bakım hizmetlerinde beceri kazanmaya yönelik hedeflerin yer aldığı bu derste, derslerin çoğunlukla teorik olarak uygulandığı ve alan uygulamasına çok az programda yer verildiği saptanmıştır.

Evde bakım hemşirelerinin hem niceliksel hem de niteliksel yönden geliştirilmeye ve desteklenmeye gereksinimi olduğunu düşünüldüğünde, bu dersin tüm hemşirelik programlarında yer alması, dersin adı, saati, içeriği ve dersin seçmeli ya da zorunlu olması gibi konularda bir standardizasyonunun sağlanması ayrıca lisansüstü eğitimde yer alan öğrenim kazanımlarının yeniden gözden geçirilmesi ve dersin işleyişinde uygulamaya yer verilmesi önerilmektedir.

\section{KAYNAKLAR}

1. Yurtsever N, Yılmaz M. Evde bakım alanında çalışan hemşirelerin çalışma koşulları, yaşadıkları güçlükler ve eğitim gereksinimlerinin belirlenmesi. İKÇÜSBFD. 2016;1(1):19-25.

2. Fadıloğlu Ç, Ertem G, Şenuzun Aykar F. Evde Sağlık ve Bakım. 1. Baskı, Göktuğ Basım Yayın ve Dağıtım, Ankara; 2013:3-55.

3. Allender JA, Rector C, Warner KD. Community and Public Health Nursing Promoting the Public's Health. 8 th ed. California: WoltersKluwer; 2010:1043-1057.

4. Sezer A, Demirbaş H, Kadıŏlu H. Evde bakım hemşireliği: mesleki yetkinlikler ve eğitim standartları. F.N. Hem. Dergisi. 2015;23(2):160-165.

5. Çoban S. Evde bakım hemşirelerinin çalışma alanında karşılaştıkları güçlüklerin ve bakım vermede duyulan gereksinim alanlarının belirlenmesi, Dokuz Eylül Üniversitesi, Yüksek Lisans Tezi, İzmir, 2013.

6. Akdemir N, Bostanoğlu H, Yurtsever S, Kutlutürkan S, Kapucu S, Canlı Özer Z. Yatağa bağımlı hastaların evde yaşadıkları sağlık sorunlarına yönelik evde bakım hizmet gereksinimleri. Dicle Tip Dergisi. 2011;38(1):57-65.

7. T.C. Sağlık Bakanlığı. Evde bakım Hizmetleri Sunumu Hakkında Yönetmelik (2005). http://www.saglik.gov.tr/TR/belge/1-570/evde-bakim hizmetlerisunumuhakkinda\%20yonetmelik.htm. Erişim tarihi 1 Ocak 2020. 
8. T.C. Sağlık Bakanlığı. Evde Sağlık Hizmetlerinin Uygulama Usul ve Esasları Hakkında Yönerge. http://www.istanbulsaglik.gov.tr/w/sb/tedk/belge/esh_y onerge.pdf. Erişim tarihi 1 Ocak 2020

9. Hemşirelik Yönetmeliğinde Değişiklik Yapılmasına Dair Yönetmelik http://www.resmigazete.gov.tr/eskiler/2011/04/201110 419-5.htm. Erişim tarihi 1 Ocak 2020

10. Katıtaş S. İstanbul'da evde bakım hemşirelerinin iş doyumu, yaşadığı güçlükler ve çözüm önerileri. Marmara Üniversitesi Halk Sağlığı Hemşireliği Anabilim Dalı, Yüksek lisans Tezi. İstanbul, 2019.
12. Friedman, Y. Mapping the literature of home health nursing. J MedLibAssoc. 2006;94(2):49-55.

13. Lundy KS, Utterback KB, Lance DK, Bloxsom IP. Home health and hospice nursing. Lundy KS, Janes S. (Eds.). Community Health Nursing Caring for the Public's Health, 2nd ed. Jones and Barletts Publishers, United States; 2009:970-977.

14. Rice, R. The Rol of The Home Care Nurse Orienation Strategies, Home Care Nursing Practice Concepts and Application. 4 th ed. Mosby, United States; 2006.

15. Yükseköğretim Bilgi Yönetim Sistemi. https://istatistik.yok.gov.tr. Erişim tarihi 1 Ocak 2020
11. Kar G. Evde bakım hizmeti veren hemşirelerin hizmetlerde yaşadıkları güçlükler ve iş doyumu düzeyleri. Yüksek Lisans Tezi, Marmara Üniversitesi Sağlık Bilimleri Enstitüsü, İstanbul, 2003. 